\title{
High Indoor Microbial Levels Are Associated with Reduced Th1 Cytokine Secretion Capacity in Infancy
}

\author{
Mikko Harri Juhani Lappalainen ${ }^{a} \quad$ Anne Hyvärinen ${ }^{a} \quad$ Maija-Riitta Hirvonen ${ }^{a}$ b \\ Helena Rintala ${ }^{a}$ Jarkko Roivainen ${ }^{a}$ Harald Renz $^{d}$ Petra Ina Pfefferle ${ }^{d}$ \\ Aino Nevalainen $^{\mathrm{a}}$ Marjut Roponen $^{\mathrm{a}}$ Juha Pekkanen ${ }^{\mathrm{a}, \mathrm{c}}$ \\ a Department of Environmental Health, National Institute for Health and Welfare, ${ }^{\mathrm{b}}$ Department of Environmental \\ Science, and ' Institute of Public Health and Clinical Nutrition, University of Eastern Finland, Kuopio, Finland; \\ ${ }^{\mathrm{d}}$ Department of Clinical Chemistry and Molecular Diagnostics, Philipp University of Marburg, Marburg, Germany
}

\section{Key Words \\ Microbial exposure $\cdot$ Cytokine $\cdot$ Immune development $\cdot$ \\ Chemical marker $\cdot$ Ergosterol $\cdot$ Muramic acid $\cdot 3$-Hydroxy \\ fatty acid $\cdot$ Mycobacterium $\cdot$ Streptomyces $\cdot$ Gram-positive bacteria}

\begin{abstract}
Background: Exposure to microbes and their components may affect the maturation of the immune system. We examined the association of house dust microbial content with cytokine-producing capacity at birth and at the age of 1 year. Methods: Production of TNF- $\alpha$, IFN- $\gamma$, IL-5, IL- 8 and IL-10 at birth $(n=228)$ and at the age of 1 year $(n=200)$ following 24- and 48-hour whole-blood stimulation with staphylococcal enterotoxin B (SEB), lipopolysaccharide and the combination of phorbol ester and ionomycin was measured. Concentrations of ergosterol (marker for fungal biomass), muramic acid (marker for Gram-positive bacteria) and 3-hydroxy fatty acids with a carbon chain length from 10 to 14 (marker for Gram-negative bacteria) in living room floor dust were analyzed using gas chromatography-tandem mass spectrometry. Five single microbial species or groups were determined using a quantitative polymerase chain reaction method. $\boldsymbol{R e}$ sults: A high total level of the studied Gram-positive bacteria
\end{abstract}

\begin{tabular}{ll}
\hline KARGER & $\begin{array}{l}\text { (c) 2012 S. Karger AG, Basel } \\
1018-2438 / 12 / 1592-0194 \$ 38.00 / 0 \quad \text { Oarger }\end{array}$ \\
$\begin{array}{l}\text { E-Mail karger@karger.ch } \\
\text { www.karger.com/iaa }\end{array}$ & $\begin{array}{l}\text { This is an Open Access article licensed under the terms of } \\
\text { the Creative Commons Attribution- NonCommercial-No- }\end{array}$ \\
& $\begin{array}{l}\text { Derivs 3.0 License (www.karger.com/OA-license), applica- } \\
\text { ble to the online version of the article only. Distribution for } \\
\text { non-commercial purposes only. }\end{array}$
\end{tabular}

in general or Mycobacterium spp. in house dust was associated with decreased SEB-stimulated IFN- $\gamma$ production, especially at the age of 1 year. The total level of indoor fungi analyzed (Penicillium spp., Aspergillus spp. and Paecilomyces variotii group, Trichoderma viride/atroviride/koningii, Wallemia sebi) was also inversely associated with IFN- $\gamma$ production at the age of 1 year, but this association did not remain significant after adjustment for potential confounders. A few associations were found between microbial exposures and other measured cytokines. Conclusions: High indoor microbial exposures may affect immune development in early life by reducing T helper type 1 cytokine secretion capacity. The observed hyporesponsiveness may reflect the adaptation of the immune system to environmental antigens. In future, more attention should be paid especially to the immunomodulatory role of exposures to Gram-positive bacteria.

Copyright $\odot 2012$ S. Karger AG, Basel

\section{Introduction}

Our understanding of the underlying mechanisms governing the general maturation of the immune system and triggering of allergic and also autoimmune diseases has increased greatly as findings emerge from new prom- 
ising areas of research relating to the expression of Tolllike receptors [1] and functions of dendritic cells [2] and $\mathrm{T}$ regulatory cells [3-5]. Increasing evidence still supports the hypothesis that exposure to microbial agents may play a crucial role in these complicated and currently poorly known immunological processes $[6,7]$.

The influence of microbial exposures on allergy development seems to be especially important during the first years of life [8]. However, these exposures can be both beneficial and harmful to health. For example, living in a moisture- and mold-damaged building seems to increase the risk of respiratory symptoms in childhood [9] and to be associated with the onset of asthma [10]. On the other hand, levels of different bacterial components in house dust are known to be associated with a reduced prevalence of wheezing [11], atopic sensitization and hay fever [12]. Even though the Gram-negative bacterial cell wall component lipopolysaccharide (LPS) is a potent respiratory irritant, continuous intensive exposure to endotoxin (bioactive LPS) may confer protection against allergy by reducing immunological responsiveness to external nonpathogenic antigens, which is reflected as downregulated immune responses in childhood (adaptation of the immune system) [12]. If one considers the known microbial agents, the effects of endotoxin exposure on health outcomes and immune functions have probably been the most extensively evaluated. Nevertheless, the environmental microbial burden also includes other potential immunomodulatory substances, such as Gram-positive bacterial matter and fungal components. Thus, a broader microbial characterization is needed to assess the possible causal relations between different microbial groups and measures of the immune system.

Our previous study indicated that exposure to house dust Gram-negative bacteria was inversely associated with the proinflammatory cytokine responses at the age of 3 months, whereas Gram-positive bacterial exposures seemed to have opposite effects on these cytokines [13]. This formed the basis for this series of investigations in which we have evaluated these respective associations in a larger number of subjects and explored whether other possible microbial groups may be associated with early immune development. Therefore, we measured concentrations of three different fungal and two Gram-positive bacterial species or groups in indoor floor dust with a quantitative polymerase chain reaction (qPCR) technique. In addition, gas chromatography-tandem mass spectrometry (GC-MS-MS) was applied to quantify the levels of chemical markers for Gram-positive and Gramnegative bacteria and for fungal biomass. Stimulated cy- tokine responses (IL-5, IL-10, TNF- $\alpha$, IFN- $\gamma$ and IL-8) were measured at birth and at the age of 1 year in order to assess neonatal immune functions.

\section{Methods}

Study Design

The participants $(n=228$; mother-child pairs from Eastern Finland) belong to a prospective birth cohort study called LUKAS2, which is an extension of the Finnish part (also called LUKAS1) of the European birth cohort study Protection against Allergy - Study in Rural Environments (PASTURE), including other mothers and their children from Austria, Switzerland, France and Germany [14]. More detailed information about the participants, recruitment process and inclusion criteria have been published previously $[9,15]$. Briefly, mothers who gave birth between May 2004 and May 2005 at Kuopio University Hospital were enrolled in this study. Mothers were given questionnaires in the last trimester of pregnancy (self-administered) and again at 2 (interview) and 12 months after delivery (self-administered). All mothers signed written informed consent. Ethical permission was granted by the Research Ethics Committee, Hospital District of Northern Savo, Kuopio, Finland.

LUKAS2 follows a similar protocol to that of the Finnish PASTURE, but only 11 out of 228 mothers were from an actively operating farm, whereas the focus of the Finnish PASTURE is on farming families. This is due to the fact that initially the LUKAS2 was established to serve a larger study population for additional studies started in the Finnish PASTURE such as more detailed assessment of dietary habits and broader determinations of moisture problems and microbial environment. In order to make housing conditions comparable between LUKAS2 and the Finnish PASTURE, only mothers not living in an apartment were invited to participate in this study. Background information concerning pet keeping and the residential area were obtained from the written questionnaires collected in the last trimester of pregnancy. Homes were inspected for moisture damage by two trained civil engineers. The self-administered questionnaire about the dust sampling included the date of the dust sampling and the use of the fireplace.

\section{Blood Sampling}

Cord blood samples from neonates $(\mathrm{n}=228)$ and peripheral venous blood samples 1 year after birth $(n=200)$ were collected in lithium-heparin tubes by an aspiration technique (Vacutainer, Becton \& Dickinson, Plymouth, UK) at the Laboratory of Kuopio University Hospital. Temporary storage and the transportation of blood samples were performed at $4^{\circ} \mathrm{C}$. Samples were processed for further analysis within $27 \mathrm{~h}$.

\section{Cytokine Measurements}

Stimulated production of TNF- $\alpha$, IFN- $\gamma$, IL-5, IL- 8 and IL-10 was analyzed from whole-blood cell culture supernatants using an enzyme immunoassay (sandwich ELISA; OptEIA ${ }^{\mathrm{TM}}$ Human ELISA set, BD Biosciences, San Diego, Calif., USA) as described previously [15]. Briefly, the production of cytokines was induced by stimulating whole-blood culture with staphylococcal enterotoxin B (SEB; final concentration $100 \mathrm{ng} / \mathrm{ml})$, LPS $(100 \mathrm{ng} / \mathrm{ml})$ or 
the combination of phorbol 12 -myristate 13 -acetate $(5 \mathrm{ng} / \mathrm{ml})$ and ionomycin $(1 \mu \mathrm{g} / \mathrm{ml}$; all from Sigma Chemicals, St. Louis, Mo., USA, except LPS, from Research Center Borstel, Borstel, Germany) with incubation times of 24 and $48 \mathrm{~h}$. The manufacturer's protocol was followed in the cytokine assay with minor modifications; optimal antibody concentrations were determined using in-house titration experiments, and the number of washes was increased. Ranges of cytokine measurements were set according to validation tests, as follows: IFN- $\gamma, 12.5-800 \mathrm{pg} / \mathrm{ml}$; IL-5, 4.7$300 \mathrm{pg} / \mathrm{ml}$; IL-8, 15.6-1,000 pg/ml; IL-10, 6.3-400 pg/ml, and TNF- $\alpha, 15.6-1,000 \mathrm{pg} / \mathrm{ml}$. Cytokine concentrations below the detection limit were given a value of $0 \mathrm{pg} / \mathrm{ml}$. If the concentration of measured cytokine exceeded the upper limit of the standard curve, the sample was diluted to obtain a concentration within the range. Individual leukocyte counts were measured from EDTA blood using a Sysmex KX-21N blood cell analyzer (Sysmex Corporation, Kobe, Japan).

Stimulated cytokine responses were available from both 24and 48-hour stimulation, but only that stimulation which had a higher response was selected for further analysis. Since higher median concentrations were detected principally following the 48-hour stimulation (data not shown), all cytokine data were selected from the 48-hour time point except for IL-10 (phorbol 12-myristate 13-acetate/ionomycin and LPS stimulation) and TNF- $\alpha$ (LPS stimulation). The data from LPS-stimulated IFN- $\gamma$ and IL-5 at birth and at the age of 1 year and SEB-induced IL-5 responses in cord blood were not included in the analysis because over $60 \%$ of the values were below the detection limits. In order to evaluate the effect of stimulation, the cytokine data were converted into $\Delta$ values (stimulated cytokine values minus unstimulated values). Negative $\Delta$ values (stimulated value smaller than unstimulated value) were given a value of $0 \mathrm{pg} / \mathrm{ml}$. In addition, the cytokine-producing capacity of leukocytes was standardized by dividing cytokine $\Delta$ values by the individual white blood cell count (picograms per $10^{6}$ white blood cells).

\section{House Dust Collection and Microbial Determinations}

Indoor dust samples $(\mathrm{n}=208)$ were collected from the living room floor 2 months after the birth of the infant. The living room was defined as the room where the family spent most of their time in the evenings after dinner. Dust samples were collected from the rug by vacuuming an area of $1 \mathrm{~m}^{2}$ for $2 \mathrm{~min}(\mathrm{n}=187)$ or, in the absence of a rug, an area of $4 \mathrm{~m}^{2}$ from the smooth floor $(\mathrm{n}=21)$. Due to the low number of smooth floor samples, the site of the sampling (floor vs. rug) was not differentiated in the statistical analyses. Microbial concentrations were calculated as the amount of microbes (cells) or amount of compounds (moles or grams) per milligram of analyzed dust. Chemical marker concentrations, namely ergosterol as a marker of fungal biomass, 3-hydroxy fatty acids with a carbon chain length from 10 to 14 [3-OH FAs $\left.\left(\mathrm{C}_{10: 0}-\mathrm{C}_{14: 0}\right)\right]$, indicating the presence of Gram-negative bacteria, and muramic acid, used to reflect the presence of Gram-positive bacteria, were determined from house dust using GC-MS-MS. Sample preparation of the chemical markers and the GC-MS-MS method for ergosterol were based on our previously described methods [13], but for analyses of muramic acid and 3-OH FAs, GC-MS-MS methods were modified to improve repeatability.

GC-MS-MS equipment consisted of a PolarisQ ion trap mass spectrometer (Thermo Electron, Austin, Tex., USA), a Trace GC Ultra gas chromatograph (Thermo Electron, Milan, Italy), a DB-
$5 \mathrm{MS}$ fused silica capillary column $(30 \mathrm{~m} \times 0.25 \mathrm{~mm} \times 0.25 \mu \mathrm{m}$; J\&W Scientific) and an AS3000 autosampler (Thermo Electron, Italy). GC was operated in the splitless mode in all methods, and the following constant parameters were used: injection volume $1 \mu \mathrm{l}$, injector temperature $280^{\circ} \mathrm{C}$, transfer tube temperature $290^{\circ} \mathrm{C}$, carrier gas (helium) flow rate $1.0 \mathrm{ml} / \mathrm{min}$ and electron ionization energy in the positive mode $70 \mathrm{eV}$. Selected reaction monitoring was also selected as the analytical approach for all targeted fragment ions. Monitored targeted fragment (and precursor) ions for the silylated markers ergosterol, muramic acid and 3-OH FAs were mass-to-charge ratio (m/z) 157.1 (m/z 363.3), m/z 127.1 (m/z 213.1) and $\mathrm{m} / \mathrm{z} 133.1$ (m/z 175.1), respectively. The silylated internal standards and fragment (and precursor) ions used for the ergosterol method were 7-dehydrocholesterol [for quantitation; $\mathrm{m} / \mathrm{z}$ 143.1 (m/z 351.3)] and cholesteryl acetate [for method sensitivity; $\mathrm{m} / \mathrm{z} 213.1$ (m/z 365.1)]; for the muramic acid method, ${ }^{13} \mathrm{C}$-labelled muramic acid derivative $[\mathrm{m} / \mathrm{z} 132.1(\mathrm{~m} / \mathrm{z} 221.1)]$, and for the $3-\mathrm{OH}$ FA method, ${ }^{13} \mathrm{C}$-labelled 3-hydroxytridecanoic acid $[\mathrm{m} / \mathrm{z} 136.1$ $(\mathrm{m} / \mathrm{z}$ 178.1)]. In the ergosterol analysis, the GC oven temperature was kept at $160^{\circ} \mathrm{C}$ for $1 \mathrm{~min}$, raised to $300^{\circ} \mathrm{C}$ in $3.5 \mathrm{~min}$ and held at $300^{\circ} \mathrm{C}$ for $7.5 \mathrm{~min}$. The ion source temperature was $250^{\circ} \mathrm{C}$, and the damping gas (helium) flow was $2.0 \mathrm{ml} / \mathrm{min}$. In the muramic acid analysis, the GC oven temperature was kept at $90^{\circ} \mathrm{C}$ for 0.5 $\mathrm{min}$, raised to $290^{\circ} \mathrm{C}$ in $5 \mathrm{~min}$ and held at $290^{\circ} \mathrm{C}$ for $4.5 \mathrm{~min}$. The ion source temperature was $280^{\circ} \mathrm{C}$, and the damping gas flow was $2.5 \mathrm{ml} / \mathrm{min}$. In the $3-\mathrm{OH} \mathrm{FA}$ analysis, the GC oven temperature was kept at $60^{\circ} \mathrm{C}$ for $0.5 \mathrm{~min}$, raised to $280^{\circ} \mathrm{C}$ in $5.5 \mathrm{~min}$ and held at $280^{\circ} \mathrm{C}$ for $3 \mathrm{~min}$. The ion source temperature was $280^{\circ} \mathrm{C}$, and the damping gas flow was $0.5 \mathrm{ml} / \mathrm{min}$.

In addition, a qPCR method [16-18] was applied to measure the concentrations (cells per milligram of dust) of the following environmental microbes with previously demonstrated importance as indoor contaminants: Mycobacterium spp. (Gram-positive bacteria, frequent environmental bacteria with immunological potential) and Streptomyces spp. (Gram-positive bacteria, frequent environmental bacteria with immunological potential) and the fungi Trichoderma viride/atroviride/koningii (T. viride group), Wallemia sebi and the combined assay group for Penicillium spp., Aspergillus spp. and Paecilomyces variotii (PenAsp group). In addition, the levels of Stachybotrys chartarum (indoor fungi associated with potential toxin production) and the assay group for Aspergillus fumigatus and Neosartorya fischeri (indoor fungi with potential toxin production and pathogenicity) were determined, but due to their rare occurrence (3.4 and 13\%, respectively, of the total 208 samples) and the low concentrations detected, these fungi were excluded from the analysis. The bacterial genus Streptomyces and all the fungi are associated with moisture damage, and many of them are also potential toxin producers.

\section{Statistical Analysis}

In some of the cytokine stimulations, there were many values below the detection limits, and therefore associations between cytokine-producing capacity and microbial exposures were first studied using the nonparametric Kruskal-Wallis test. In this screening phase, the most consistent associations were found in SEB-induced IFN- $\gamma$ responses, which were thus selected for covariance analyses. Prior to these parametric tests, cytokine concentrations were natural log-transformed to obtain more normally distributed data. However, an approximate normal distribution for natural log-transformed SEB-induced IFN- $\gamma$ re- 
Table 1. Concentrations of different microbial species and chemical markers in floor dust samples

\begin{tabular}{|c|c|c|c|c|c|c|c|}
\hline & $\begin{array}{l}\text { Number } \\
\text { of samples }\end{array}$ & Unit & Min. & $\begin{array}{l}25 \text { th } \\
\text { percentile }\end{array}$ & Median & $\begin{array}{l}75 \text { th } \\
\text { percentile }\end{array}$ & Max. \\
\hline \multicolumn{8}{|l|}{ Microbial species } \\
\hline Mycobacterium spp. & 207 & cells/mg & 0 & 1,150 & 3,570 & 8,510 & 223,000 \\
\hline PenAsp group & 207 & cells/mg & 0 & 32.5 & 100 & 429 & 7,460 \\
\hline Streptomyces spp. & 207 & cells/mg & 0 & 46.7 & 115 & 427 & 49,800 \\
\hline T. viride group & 208 & cells/mg & 0 & 1.39 & 10.4 & 60.3 & 24,900 \\
\hline W. sebi & 208 & cells/mg & 0 & 0 & 2.69 & 13.7 & 11,500 \\
\hline \multicolumn{8}{|l|}{ Chemical markers } \\
\hline Ergosterol & 196 & $\mathrm{ng} / \mathrm{mg}$ & 0.29 & 7.03 & 11.2 & 16.5 & 71.0 \\
\hline Muramic acid & 179 & $\mathrm{ng} / \mathrm{mg}$ & 0 & 15.3 & 21.5 & 31.5 & 75.3 \\
\hline 3-OH FAs $\left(\mathrm{C}_{10: 0}-\mathrm{C}_{14: 0}\right)$ & 191 & $\mu \mathrm{mol} / \mathrm{mg}$ & 0 & 14.1 & 37.1 & 70.3 & 362 \\
\hline
\end{tabular}

Min. $=$ Minimum; Max. $=$ maximum.

sponses in cord blood was obtained only after exclusion of the values under the detection limit $(n=20 ; 12 \%$ of the total). Based on our earlier results, and using the current data and knowledge about the biologically plausible effects on immune responses, the following confounders were included in all multivariate models: gender of the child, mode of birth, number of earlier deliveries (4 groups: $0 / 1 / 2 / \geq 3$ ), use of antibiotics during pregnancy, maternal atopy (any serum-specific $\operatorname{IgE} \geq 0.35 \mathrm{kU} / \mathrm{l}$ ), maternal doctor-diagnosed asthma, maternal education (comprehensive school, vocational school, upper secondary school or academic), number of siblings aged $\leq 12$ years living in the household ( 3 groups: $0 / 1 / \geq 2$ ) and maternal smoking (4 groups: never smoked over 5 packets of cigarettes/given up smoking/given up smoking during pregnancy/smoked during pregnancy). These adjustments had very little effect on the effect estimates reported.

Households were classified into 3 categories of microbial exposure (low, medium and high) using upper and lower quartiles of microbial concentrations (table 1 ) as cutoff points (low $<25 \%$; medium $=25-75 \%$; high $>75 \%$ ). Since $36 \%$ of the measured concentrations of $W$. sebi were under the detection limit, the categories of low and medium were combined for W. sebi. In addition, to measure overall microbial exposures, categories of microbial variables were numbered (low $=1$; medium $=2$; high $=3$ ), summed and further divided into tertiles. Four combined variables were created: combined Gram-positive bacteria (range 3-9), combined indoor fungi (range 3-8), combined fungi (range 4-11) and combined chemical markers (range 3-9). Nonparametric tests (MannWhitney or Kruskal-Wallis) were used when microbial concentrations were evaluated in relation to residential area (3 groups: city, suburb; countryside, population center; countryside, sparsely populated area), observed moisture damage in the living room (no damage $/ \mathrm{mild} /$ severe damage), fireplace in use (yes/no), season of the dust sampling (winter $=$ December-February; spring $=$ March-May; summer = June-August; autumn = September-November) and dog/cat ownership. Most of the 12 families that reported living in city centers were actually living in small towns near the city of Kuopio; thus, households from city centers and suburbs were combined in analysis. Correlations between microbial concentrations were investigated by calculating Spearman's

Microbial Exposure and Immune

Development rank correlation coefficients. Statistical analyses were carried out using the Statistical Package for the Social Sciences software version 17.0 for Windows (SPSS Inc., Chicago, Ill., USA). $\mathrm{p} \leq 0.05$ was considered statistically significant.

\section{Results}

\section{Determinants for Microbial Concentrations}

Quartiles and minimum and maximum concentrations for each microbial species and chemical markers determined from the indoor floor dust are presented in table 1. Median microbial concentrations were generally higher in countryside households compared to households in suburbs (online suppl. table S1; for all online supplementary material, see www. karger.com/doi/10.1159/000335596). In addition, higher microbial levels were observed in sparsely populated areas in the countryside than in population centers. The presence of severe moisture damage seemed to increase the levels of Streptomyces spp. and ergosterol in house dust. If a fireplace was in use in the household, then the microbial concentrations were generally higher. The season of dust sampling had an influence on some of the microbial concentrations. Levels of Mycobacterium spp., Streptomyces spp. and the T. viride group were statistically significantly higher in families with $\operatorname{dog}(\mathrm{s})$ compared to non-dog owners. Cat ownership did not have an influence on the measured microbial concentrations.

\section{Correlations between Microbial Concentrations}

Levels of Streptomyces spp. and the PenAsp group correlated statistically significantly with the concentrations 
Table 2. Spearman's correlation coefficients between concentrations of different microbial species and groups and chemical markers determined from floor dust samples

\begin{tabular}{|c|c|c|c|c|c|c|c|}
\hline & $\begin{array}{l}\text { Mycobacterium } \\
\text { spp. }\end{array}$ & $\begin{array}{l}\text { PenAsp } \\
\text { group }\end{array}$ & $\begin{array}{l}\text { Streptomyces } \\
\text { spp. }\end{array}$ & $\begin{array}{l}\text { T. viride } \\
\text { group }\end{array}$ & W. sebi & Ergosterol & $\begin{array}{l}\text { Muramic } \\
\text { acid }\end{array}$ \\
\hline PenAsp group & $0.36^{* *}$ & & & & & & \\
\hline Number of samples & 207 & & & & & & \\
\hline Streptomyces spp. & $0.52^{* *}$ & $0.43^{* *}$ & & & & & \\
\hline Number of samples & 207 & 207 & & & & & \\
\hline W. sebi & 0.13 & $0.38^{* *}$ & $0.21^{*}$ & 0.06 & & & \\
\hline Number of samples & 207 & 207 & 207 & 208 & & & \\
\hline Ergosterol & $0.29^{* *}$ & $0.26^{* *}$ & $0.38^{* *}$ & 0.03 & 0.08 & & \\
\hline Number of samples & 194 & 194 & 194 & 195 & 195 & & \\
\hline Muramic acid & $0.32^{* *}$ & $0.25^{* *}$ & $0.26^{* *}$ & 0.07 & $0.23^{*}$ & 0.07 & \\
\hline Number of samples & 178 & 178 & 178 & 179 & 179 & 178 & \\
\hline
\end{tabular}

of all the measured microbial agents (table 2). The combined $T$. viride assay group did not correlate with W. sebi or with the concentrations of chemical markers. The marker for fungal biomass (ergosterol) correlated with the PenAsp group and with the two bacterial genera (Streptomyces spp. and Mycobacterium spp.). Both of the Gram-positive bacterial genera measured with qPCR and two of the fungi (W. sebi and PenAsp group) correlated with the concentrations of the Gram-positive bacterial marker (muramic acid). Levels of $W$. sebi displayed the poorest correlations. The total amount of collected floor dust correlated significantly with the concentrations of Mycobacterium spp. (Spearman's rank $\mathrm{r}=0.18, \mathrm{p}=0.01$ ), Streptomyces spp. $(\mathrm{r}=0.26, \mathrm{p}<0.01)$, the T. viride group $(\mathrm{r}=0.19, \mathrm{p}=0.01)$ and muramic acid $(\mathrm{r}=0.27, \mathrm{p}<0.01)$.

\section{Associations between Bacterial Exposures and Cytokine Responses}

Children with high exposure to house dust Streptomyces spp. expressed the lowest SEB-stimulated IFN- $\gamma$ levels at birth (table 3). Similar associations were found with the combined microbial variable for Gram-positive bacterial exposure (fig. 1). However, both the associations became weaker after multivariable adjustment for potential confounders (table 3). In addition, the levels of Mycobacterium spp., the combined variable for Gram-positive bacterial exposure and the combined chemical markers variable were inversely associated with the levels of LPS- stimulated IL-8 in cord blood (online suppl. tables S2 and S3). Other cord blood cytokines were not consistently associated with the floor dust bacterial levels (online suppl. table S2).

With regard to the assessments in the 1-year-old children, concentrations of Mycobacterium spp. were associated with decreased SEB-induced IFN- $\gamma$-producing capacity (fig. 1). Controlling for confounders had only a minor influence on the observed association (table 3). Similarly to the situation at birth, an inverse association was detected between the combined Gram-positive bacterial variable and IFN- $\gamma$ responses at the age of 1 year (fig. 1). Multivariable adjustment did not alter this result (table 3). Except for IFN- $\gamma$, cytokine-producing capacity at the age of 1 year did not seem to differ consistently in relation to bacterial exposures (online suppl. table S4). Exposure to muramic acid and 3-OH FAs did not have any clear effect on cytokine responses at birth or 1 year after birth.

\section{Associations between Fungal Exposures and Cytokine Responses}

Concentrations of single fungal groups or species were not consistently associated with any of the measured cytokine responses either at birth or at the age of 1 year (table 3; online suppl. tables S3 and S5). An inverse dosedependent relation was found between the combined fungal exposure variable and SEB-stimulated IFN- $\gamma$ secretion capacity at birth (table 3). In addition, increased 
Table 3. Median concentrations and multivariate adjusted associations between microbial exposures and SEB-stimulated IFN- $\gamma$ responses at birth and at the age of 1 year

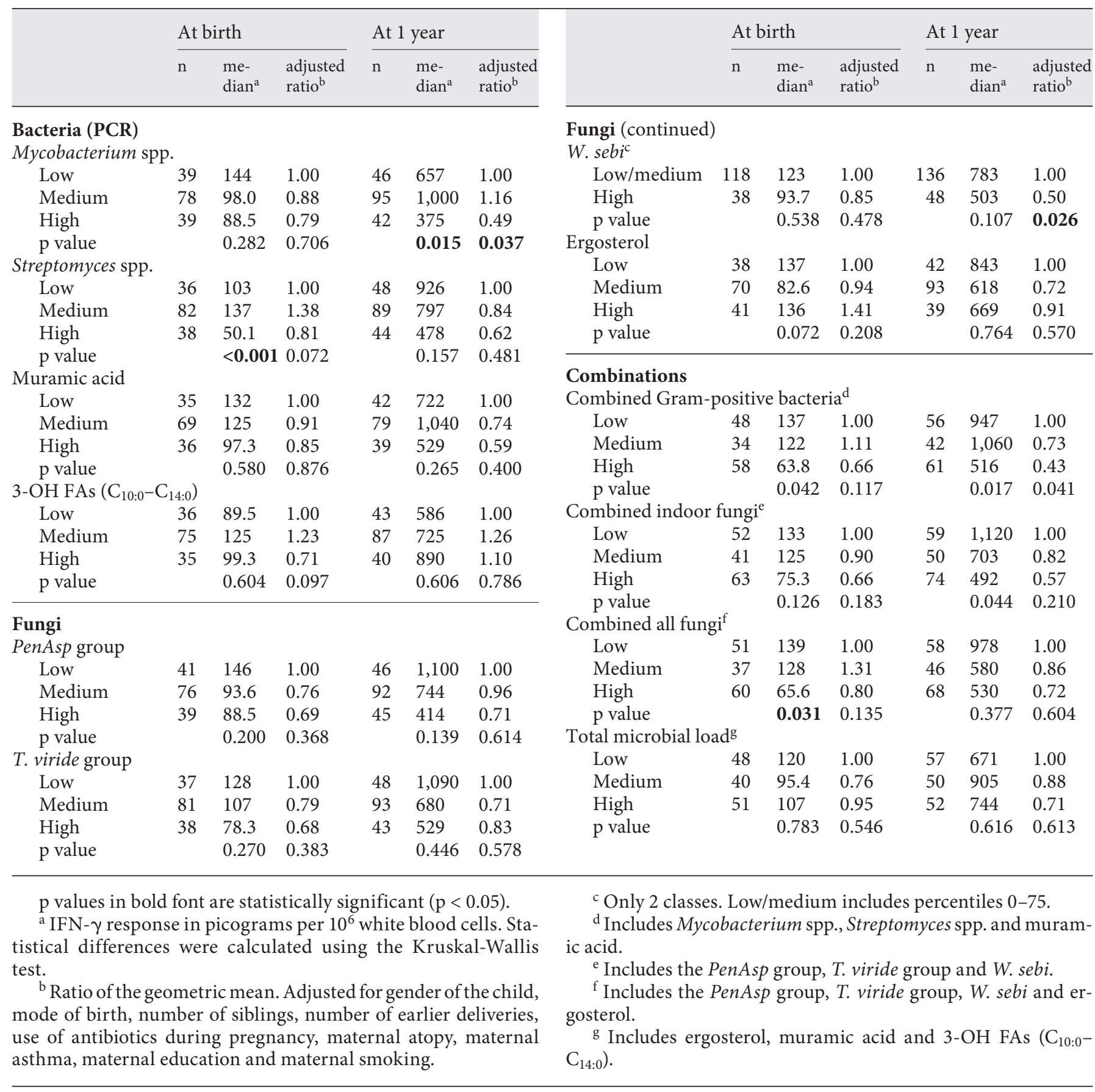

exposure to indoor fungi in general (combined indoor fungi variable) was associated with a decrease in IFN- $\gamma$ responses at the age of 1 year (table 3). However, after multivariable adjustment for confounders, statistical significance was no longer achieved. In addition, although statistical significance was reached only for W. sebi (table 3; adjusted association), most of the single fungal groups seemed to follow a similar trend for their effect on IFN- $\gamma$. Interestingly, all of the measured cytokines in cord blood following stimulation with SEB showed statis- 


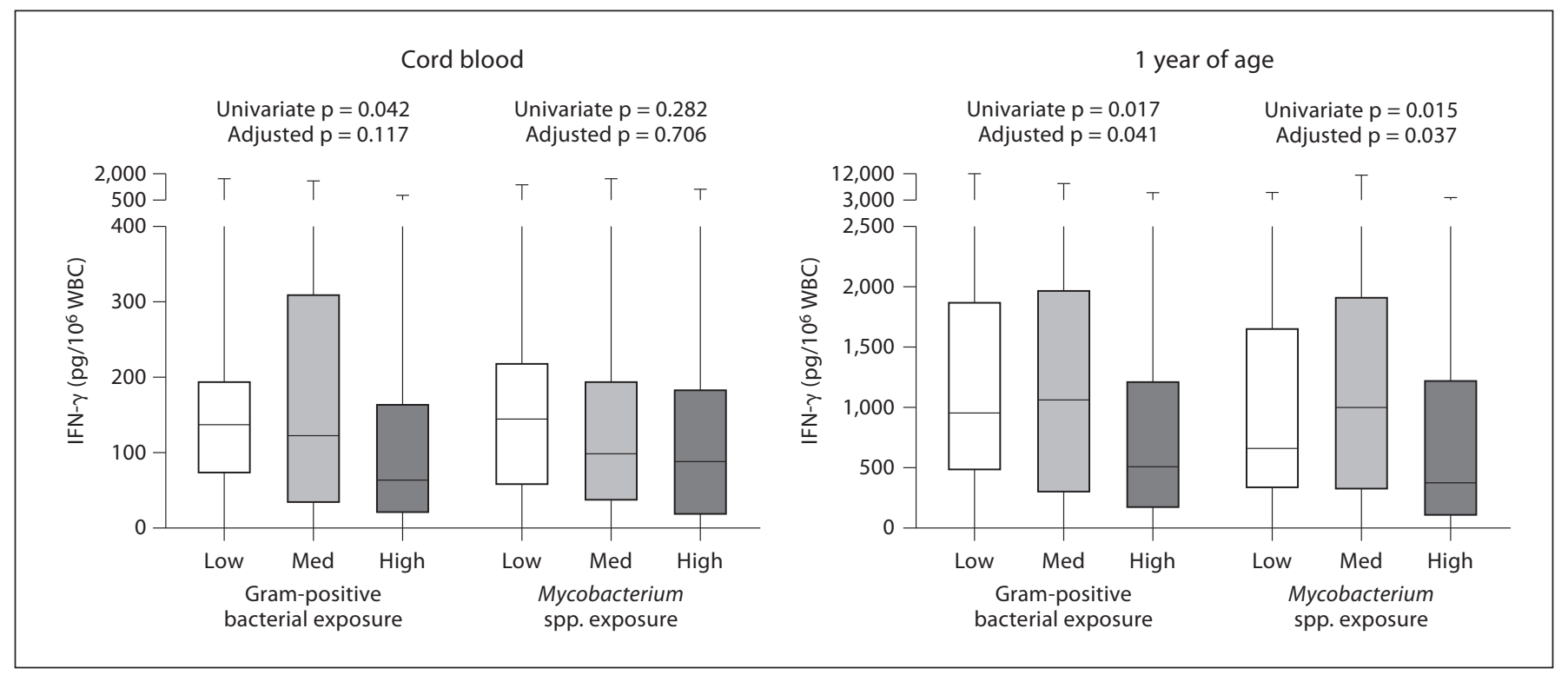

Fig. 1. SEB-induced (48-hour) IFN- $\gamma$-producing capacity at birth and 1 year after birth in relation to exposure to indoor dust Grampositive bacteria and Mycobacterium spp. Box plots represent the interquartile range, median (horizontal line) and extremes (whis-

tically significant U-shaped associations with the levels of ergosterol (online suppl. table S3).

Associations between microbial exposures and cytokine responses were also investigated by calculating microbial levels against the vacuumed floor area $\left(1\right.$ or $\left.4 \mathrm{~m}^{2}\right)$, and findings were quite similar; SEB-induced IFN- $\gamma$ responses were decreased with increasing microbial concentrations, though the associations seemed to be stronger at birth than at the age of 1 year. No consistent associations were found between microbial exposures and other measured cytokines (data not shown).

\section{Discussion}

The present multidisciplinary approach using an epidemiological prospective study design along with microbiological and immunological methods offers unique information about the associations between immune responses in early life and different indoor microbial exposures. Our findings suggest that exposure to increased indoor microbial concentrations may result in decreased Thelper type 1 (Th1) cytokine secretion capacity during the first year of life. If microbes were assessed as either general fungal or general Gram-positive bacterial exposure (combined indoor fungi, combined fungi kers) of individual cytokine $\Delta$ values. Univariate $\mathrm{p}$ values were calculated using the Kruskal-Wallis test. Adjusted p values were calculated by linear regression. Med. = Medium; $\mathrm{WBC}=$ white blood cells. and combined Gram-positive bacteria variables), parallel downregulating effects on IFN- $\gamma$ responses were observed. In addition, most of the separate microbial species and groups showed similar trends, but the associations were statistically significant only for Gram-positive bacteria; children exposed to high concentrations of Streptomyces spp. had the lowest IFN- $\gamma$ responses at birth, whereas Mycobacterium spp. exposure was associated with attenuated IFN- $\gamma$-producing capacity at the age of 1 year. However, after multivariable adjustment for several potential confounders, the associations were statistically significant only for Mycobacterium spp. and the combined Gram-positive bacterial variable. As far as we are aware, this is the first publication describing associations between immune responses in early life and the concentrations of specific microbial species/groups in house dust in an epidemiological study design.

Immune responsiveness to different types of antigens in early life was studied by stimulating whole-blood samples with SEB (superantigen of Gram-positive bacterial origin, activates cells in both innate and adaptive immunity), Gram-negative bacterial LPS (Gram-negative bacterial origin, stimulates innate immunity) and the combination of mitogenic phorbol 12-myristate 13-acetate and the calcium ionophore ionomycin (induces adaptive $\mathrm{T}$ cell responses). It is noteworthy that decreased IFN- $\gamma$ 
levels were detected following stimulation with the Grampositive bacterial SEB. Hyporesponsiveness to SEB stimulation in a cytokine assay may indicate that repeated high-level exposure to indoor Gram-positive bacterial matter such as Mycobacterium spp. or Streptomyces spp. early in life promotes the adaptation of the immune system against nonpathogenic antigens. This immunological adaptation process may be beneficial for normal immune development and protection against allergy. The concept of immunologic adaptation against microbial agents was previously introduced by the study by BraunFahrländer et al. [12], which suggested that continuous exposure to house dust endotoxin leads to the general suppression of cytokine production (TNF- $\alpha$, IFN- $\gamma$, IL10 and IL-12) and further decreases the risk of atopic sensitization, atopic asthma, atopic wheeze and hay fever in childhood. Moreover, it seems that increased exposure to muramic acid in mattress dust decreases the prevalence of wheezing in childhood [11], which indicates that exposure to Gram-positive bacteria may confer a protective effect against respiratory disorders.

IFN- $\gamma$ plays a crucial role in combating intracellular pathogenic microbes. The main sources of IFN- $\gamma$ are Th1 cells and natural killer cells. In innate immunity, IFN- $\gamma$ is the principal macrophage-activating cytokine, and in adaptive immunity, it promotes the development of naive T cells to Th1 cells and inhibits Th 2 differentiation. Thus, it is also possible that the downregulation of Th1 cytokine responses in infancy observed here is not beneficial for the normal maturation process of the immune system, because it may increase the risk of allergic disorders by favoring the augmentation of allergy-promoting Th2type responses. In fact, species of the genus Streptomyces have been isolated from moisture-damaged buildings [19] in which the occupants have experienced symptoms. Studies conducted in mouse cell lines indicate that the spores of Streptomyces californicus express cytotoxic, cytostatic and genotoxic properties [20-22]. Furthermore, in mouse models, increased proinflammatory cytokine secretion, inflammation and systemic immunotoxicity have been reported following instillation of S. californicus spores $[23,24]$.

The prevailing hypothesis for the increased prevalence of childhood asthma and allergies and possibly also Th1mediated autoimmune disorders in modern Western societies is based on reduced microbial exposures and infections [25-27]. Related to this phenomenon, the influence of childhood mycobacterial infections on atopy has been studied widely, but the results seem to be somewhat controversial [28]. The majority of the research has been

Microbial Exposure and Immune

Development focused specifically on Mycobacterium tuberculosis infections. However, it should be noted that indoor dust includes several nonpathogenic mycobacterial species (e.g. the very common Mycobacterium terrae [17]) that seem to be capable of immunomodulation in animal and cell line studies $[29,30]$. In addition, different species of $M y$ cobacterium seem to induce cytokine secretion, e.g. IL-8, differentially in vitro [31], which makes it even more difficult to assess the true contribution of Mycobacterium spp. exposure to immune maturation. Since fungal levels also seemed to exhibit a similar effect on the IFN- $\gamma$ secretion capacity and because significant correlations were found between microbial variables, the true contribution of bacterial exposures, especially of Gram-positive origin, needs to be clarified. In addition, it remains unclear whether this attenuation of Th1 responses following continuous intensive microbial exposures in indoors is harmful or not to immune development and human health.

Lipid A, which is the toxic part of the Gram-negative bacterial cell wall component LPS, contains 3-OH FAs; thus, 3-OH FAs are regarded as a marker for Gram-negative bacteria $[32,33]$. Due to the high correlation with Limulus activity, 3-OH FAs with a carbon chain length from 10 to 14 seem to be an appropriate marker for bioactive endotoxin [32]. In the present study, the levels of 3-OH FAs $\left(\mathrm{C}_{10: 0}-\mathrm{C}_{14: 0}\right)$ in floor dust did not have a consistent influence on the cytokine secretion capacity at birth or at the age of 1 year. Similarly, no associations were found between the levels of floor dust 3-OH FAs $\left(\mathrm{C}_{10: 0}-\mathrm{C}_{14: 0}\right)$ and cytokine responses (IFN- $\gamma, \mathrm{TNF}-\alpha$ and IL-6) at the age of 3 months in our earlier study [13], but instead there was an inverse association between bed dust 3-OH FA concentrations and proinflammatory cytokine responses. The divergent findings between bed dust and floor dust samples may be due to different sources of bacteria; $86 \%$ of the Gram-negative bacteria in bed dust originate from human sources, whereas $79 \%$ of floor dust Gram-negative bacterial species are from environmental sources [34]. Furthermore, Gram-negative bacteria account for only $21 \%$ of the floor dust and $8 \%$ of the bed dust bacteria [34]. The corresponding numbers for the occurrence of Gram-positive bacteria are 74\% [35] to 79\% [34] for floor dust and 92\% [34] for bed dust, which indicates that the bacterial flora in house dust of dwellings is dominated by bacteria of Gram-positive origin. Since characterization of the house dust Gram-negative bacterial species was limited in our study (only 3-OH FAs represented Gram-negative bacterial exposure), it was not possible to investigate if the exposure to different Gramnegative species/groups is associated with the immune 
responses in early life. Because there were significant correlations between microbial levels (table 3 ), the associations found in the present study may be a result of the exposure to a broader spectrum of microbes than Grampositive bacteria alone, including also Gram-negative bacterial exposures. However, due to the predominance of Gram-positive bacteria in indoor dust and the potential immunomodulatory properties observed in this study, more attention should be paid to the possible health effects (protective or adverse) caused by Gram-positive bacterial exposures.

We did not detect any consistent associations between the separate fungal exposures and cytokine responses. However, SEB-induced IFN- $\gamma$ responses showed a decreasing trend for all the measured fungal species and groups. Associations between exposure to specific fungal species (determined using qPCR) and other cytokines were mostly U-shaped. Similarly to the qPCR results, some U-shaped associations were detected between the levels of ergosterol (marker for fungal biomass) and immune responses at birth but not at 1 year of age. Furthermore, exposure to ergosterol has not been linked to the production of cytokines at birth [13], at 3 months of age [13], at 1 year of age [36] or at 3 years of age [36]. However, even though the results were not very consistent, recent findings from the PASTURE core study do indicate that the levels of fungal extracellular polysaccharides measured from smooth floor may be associated with increased cord blood TNF- $\alpha$ responses [37]. It has been speculated that exposure to ergosterol may increase the risk of sensitization against fungi and wheezing in adulthood [38]. Despite the lack of firm evidence concerning the effects of fungal exposures on immune responses emerging from this study, living in a moisture-damaged building and the presence of mold seem to increase the risk of respiratory symptoms, but rarely allergic sensitization, in childhood $[9,39]$. In addition, previous in vitro [40] and in vivo [41] studies imply that fungal components derived from moldy buildings have a real capacity to evoke severe health problems. However, further studies are needed to investigate the extent to which fungal exposures affect immune development and the health of newborns.

We did not find any consistent associations between microbial exposures and Th2-type responses, measured as stimulated production of IL-5. Inclusion of other Th2 cytokines, such as IL-4 and IL-13, could provide additional information about the Th2 immune status of children and its relation to environmental exposures. This study followed the protocol of the larger European Union- funded project (PASTURE), in which only five cytokines were analyzed, but Th2 responses will be measured in more detail in our future studies. In addition, more attention will be paid to immune-regulatory mechanisms such as regulatory T cells; since both the prevalence of Th2related diseases such as allergies and Th1-mediated autoimmune diseases such as Crohn's disease and type I diabetes have increased during the past decades concomitantly with the decrease in infections and environmental exposure to microbial compounds [27], the cellular mechanisms underlying the protective effect of these exposures are likely to extend beyond Th1/Th2 immune deviation.

In conclusion, the observed associations indicate that intense microbial exposures may contribute to the immune development during the first year of life by reducing Th1 cytokine (IFN- $\gamma$ ) production capacity. The role of Gram-positive bacterial exposures seems to be especially important because the associations were strongest with bacterial species of Gram-positive origin and, interestingly, those associations were seen specifically in IFN$\gamma$ responses stimulated by Gram-positive bacterial SEB. Continuous high-level exposure to microbes may lead to downregulated Th1 responses. The observed hyporesponsiveness could reflect the adaptation of the immune system to external nonpathogenic antigens. More investigations will be needed to clarify the true contribution of different microbial exposures to immunologic maturation in infancy.

\section{Acknowledgements}

The authors wish to acknowledge all the participating families for their cooperation. The help of Pekka Tiittanen, MSc, and Asko Vepsäläinen, MSc, with data management and statistical analysis is highly appreciated. Timo Kauppila, MSc, is also acknowledged for his help with data management. We are also particularly grateful to Ms. Reetta Tiihonen and Ms. Heli Martikainen for their excellent technical assistance and to study nurse Ms. Raija Juntunen for organizing the fieldwork. Finally, special thanks belong to the PASTURE study group for successful collaboration.

This work was supported by the Kuopio University Hospital (EVO grant), National Institute for Health and Welfare, Finland, Graduate School in Environmental Health (SYTYKE), the Academy of Finland (grant 111177) and the European Commission as part of the project Health Effects of Indoor Pollutants: Integrating Microbial, Toxicological and Epidemiological Approaches (grant agreement No. 211488 under the Seventh Framework Programme, Topic ENV.2007.1.2.1.1.: Indoor air pollution in Europe: An emerging environmental health issue). 


\section{References}

$>1$ Bauer S, Hangel D, Yu P: Immunobiology of 16 Rintala H, Nevalainen A: Quantitative meatoll-like receptors in allergic disease. Immunobiology 2007;212:521-533.

-2 Lambrecht BN, Hammad H: Biology of lung dendritic cells at the origin of asthma. Immunity 2009;31:412-424.

$\checkmark 3$ Seroogy CM, Gern JE: The role of T regulatory cells in asthma. J Allergy Clin Immunol 2005;116:996-999.

-4 Stock P, DeKruyff RH, Umetsu DT: Inhibition of the allergic response by regulatory $\mathrm{T}$ cells. Curr Opin Allergy Clin Immunol 2006;6:12-16.

5 Ling EM, Smith T, Nguyen XD, et al: Relation of CD4+CD25+ regulatory T-cell suppression of allergen-driven T-cell activation to atopic status and expression of allergic disease. Lancet 2004;363:608-615.

$\checkmark 6$ Schaub B, Lauener R, von Mutius E: The many faces of the hygiene hypothesis. J Allergy Clinical Immunol 2006;117:969-977; quiz 978.

7 Björksten B: The hygiene hypothesis: do we still believe in it? Nestle Nutr Workshop Ser Pediatr Program 2009;64:11-18, discussion 18-22, 251-257.

$>8$ Riedler J, Braun-Fahrlander C, Eder W, et al: Exposure to farming in early life and development of asthma and allergy: a cross-sectional survey. Lancet 2001;358:1129-1133.

$>9$ Karvonen AM, Hyvärinen A, Roponen M, et al: Confirmed moisture damage at home, respiratory symptoms and atopy in early life: a birth-cohort study. Pediatrics 2009; 124:e329-e338.

$\checkmark 10$ Pekkanen J, Hyvärinen A, HaverinenShaughnessy U, Korppi M, Putus T, Nevalainen A: Moisture damage and childhood asthma: a population-based incident casecontrol study. Eur Respir J 2007;29:509-515.

11 van Strien RT, Engel R, Holst O, et al: Microbial exposure of rural school children, as assessed by levels of $\mathrm{N}$-acetyl-muramic acid in mattress dust, and its association with respiratory health. J Allergy Clin Immunol 2004 113:860-867.

$>12$ Braun-Fahrländer C, Riedler J, Herz U, et al: Environmental exposure to endotoxin and its relation to asthma in school-age children. N Engl J Med 2002;347:869-877.

$\checkmark 13$ Lappalainen MH, Roponen M, Hyvärinen A, et al: Exposure to environmental bacteria may have differing effects on tumour necrosis factor-alpha and interleukin-6-producing capacity in infancy. Clin Exp Allergy 2008;38:1483-1492.

14 von Mutius E, Schmid S: The PASTURE project: EU support for the improvement of knowledge about risk factors and preventive factors for atopy in Europe. Allergy 2006;61 407-413.

-15 Lappalainen M, Roponen M, Pekkanen J, Huttunen K, Hirvonen MR: Maturation of cytokine-producing capacity from birth to 1 year of age. Pediatr Allergy Immunol 2009; 20:714-725. surement of streptomycetes using real-time PCR. J Environ Monit 2006;8:745-749.

17 Torvinen E, Torkko P, Rintala AN: Real-time PCR detection of environmental mycobacteria in house dust. J Microbiol Methods 2010; 82:78-84

18 Haugland RA, Varma M, Wymer LJ, Vesper SJ: Quantitative PCR analysis of selected Aspergillus, Penicillium and Paecilomyces species. Syst Appl Microbiol 2004;27:198-210. nen A: Detection of streptomycetes in house dust - comparison of culture and PCR methods. Indoor Air 2004;14:112-119.

20 Penttinen P, Pelkonen J, Huttunen K, Toivola M, Hirvonen MR: Interactions between Streptomyces californicus and Stachybotrys chartarum can induce apoptosis and cell cycle arrest in mouse RAW264.7 macrophages Toxicol Appl Pharmacol 2005;202:278-288.

21 Penttinen P, Pelkonen J, Huttunen K, Hirvonen MR: Co-cultivation of Streptomyces californicus and Stachybotrys chartarum stimulates the production of cytostatic compound(s) with immunotoxic properties. Toxicol Appl Pharmacol 2006;217:342-351.

22 Penttinen P, Tampio M, Mäki-Paakkanen J, Vähäkangas K, Pelkonen J, Hirvonen MR DNA damage and p53 in RAW264.7 cells induced by the spores of co-cultivated Streptomyces californicus and Stachybotrys chartarum. Toxicology 2007;235:92-102.

23 Jussila J, Komulainen H, Huttunen K, et al: Inflammatory responses in mice after intratracheal instillation of spores of Streptomyces californicus isolated from indoor air of a moldy building. Toxicol Appl Pharmacol 2001;171:61-69.

24 Jussila J, Pelkonen J, Kosma VM, MäkiPaakkanen J, Komulainen H, Hirvonen MR Systemic immunoresponses in mice after repeated exposure of lungs to spores of Strep tomyces californicus. Clin Diagn Lab Immunol 2003;10:30-37.

25 Strachan DP: Family size, infection and atopy: the first decade of the 'hygiene hypothesis'. Thorax 2000;55(suppl 1):S2-S10.

26 Martinez FD, Holt PG: Role of microbial burden in aetiology of allergy and asthma. Lancet 1999;354(suppl 2):SII12-SII15.

27 Bach JF: The effect of infections on susceptibility to autoimmune and allergic diseases. N Engl J Med 2002;347:911-920.

-28 Obihara CC, Bollen CW, Beyers N, Kimpen JL: Mycobacterial infection and atopy in childhood: a systematic review. Pediatr Allergy Immunol 2007;18:551-559.

29 Jussila J, Komulainen H, Huttunen K, et al: Mycobacterium terrae isolated from indoor air of a moisture-damaged building induces sustained biphasic inflammatory response in mouse lungs. Environ Health Perspect 2002;110:1119-1125.
19 Rintala H, Hyvärinen A, Paulin L, Nevalai-
30 Huttunen K, Jussila J, Hirvonen MR, Iivanainen E, Katila ML: Comparison of mycobacteria-induced cytotoxicity and inflammatory responses in human and mouse cell lines. Inhal Toxicol 2001;13:977-991.

-31 Song CH, Lee JS, Kim HJ, Park JK, Paik TH, Jo EK: Interleukin- 8 is differentially expressed by human-derived monocytic cell line U937 infected with Mycobacterium tuberculosis H37Rv and Mycobacterium marinum. Infect Immun 2003;71:5480-5487.

32 Saraf A, Larsson L, Burge H, Milton D: Quantification of ergosterol and 3-hydroxy fatty acids in settled house dust by gas chromatography-mass spectrometry: comparison with fungal culture and determination of endotoxin by a Limulus amebocyte lysate assay. Appl Environ Microbiol 1997;63: 2554-2559.

33 Binding N, Jaschinski S, Werlich S, Bletz S, Witting U: Quantification of bacterial lipopolysaccharides (endotoxin) by GC-MS determination of 3-hydroxy fatty acids. J Environ Monit 2004;6:65-70.

34 Täubel M, Rintala H, Pitkäranta M, et al: The occupant as a source of house dust bacteria. J Allergy Clin Immunol 2009;124:834-840, e847.

35 Rintala H, Pitkäranta M, Toivola M, Paulin L, Nevalainen A: Diversity and seasonal dynamics of bacterial community in indoor environment. BMC Microbiol 2008;8:56

-36 Bufford JD, Reardon CL, Li Z, et al: Effects of dog ownership in early childhood on immune development and atopic diseases. Clin Exp Allergy 2008;38:1635-1643.

37 Pfefferle PI, Büchele G, Blümer N, et al: Cord blood cytokines are modulated by maternal farming activities and consumption of farm dairy products during pregnancy: the PASTURE Study. J Allergy Clin Immunol 2010; 125:108-115.e1-3.

38 Dharmage S, Bailey M, Raven J, et al: Current indoor allergen levels of fungi and cats, but not house dust mites, influence allergy and asthma in adults with high dust mite exposure. Am J Respir Crit Care Med 2001;164: 65-71.

39 World Health Organization: WHO Guidelines for Indoor Air Quality: Dampness and Mould. Copenhagen, WHO Regional Office for Europe, 2009.

40 Huttunen K, Hyvärinen A, Nevalainen A, Komulainen H, Hirvonen MR: Production of proinflammatory mediators by indoor air bacteria and fungal spores in mouse and human cell lines. Environ Health Perspect 2003;111:85-92.

41 Jussila J, Komulainen H, Kosma VM, Nevalainen A, Pelkonen J, Hirvonen MR: Spores of Aspergillus versicolor isolated from indoor air of a moisture-damaged building provoke acute inflammation in mouse lungs. Inhal Toxicol 2002;14:1261-1277. 